\title{
Non-Linear Static Analysis of Off-Road Vehicle Cabin ROPS Structure Using Finite Element Method
}

\author{
Rajesh Kumar. $\mathbf{T}^{1^{*}}$, Haridass. $\mathbf{R}^{2}$, Dhandapani. N. $\mathbf{V}^{3}$, Dinakar. $\mathbf{M}^{4}$ \\ ${ }^{1,2}$ Assistant Professor, ${ }^{3}$ Professor, ${ }^{4} U G$ Student, Department of Mechanical Engineering, \\ Karpagam College of Engineering, Coimbatore, India
}

\begin{abstract}
The passive safety of operator is an important parameter to be evaluated when an automotive is considered. During life-threatening situations like vehicle rollovers, the safety of the operator can be ensured by the design of protective structure. The protective structure that safeguards the operator, is either an integral part of the cabin of the operator or an external structure outside the operator's compartment. The major accidents occurring in military, construction and mining operations are disastrous due to absence of this structure. Thus an effective ROPS (Roll Over Protective structure) along with the corresponding FOPS (Fall Over Protective Structure) can be used for saving lives.
\end{abstract}

Index Terms: Passive safety, Protective structure, ROPS, FEA.

\section{Introduction}

In mining machines and heavy earthmovers there is a compartment, in which the operator operates. The protection of the compartment is vital, to save the lives of the operators and to avoid major fatal accidents. During operations, the life of operator comes into risk in a number of extreme situations. One of them is when moving over uneven earth surfaces the rolling of the machine takes place. Another one is, in mining caves, the heavy large pieces of earth masses falls over the compartment.

Thus the protective compartment must have the capacity to transfer the quantity of loads over it. The analysis result satisfies in accordance with the ISO standards.

\section{Literature Review}

During engineering work in construction and mining, protective structures are vital to provide safety to operator in case of a rollover (ROPS - ISO 3471) and to protect the construction machines against the falling objects (FOPS - ISO 3449). In the operations of mining machines, higher safety at impact energies must be ensured than the specified by ISO 3449 . This is done because of the operating conditions and risks of rock slides. [1] Depending on the applications, the operator's cabin must have adjustable height that increases the field view of the operator while drilling blast holes. But, a number of problems are caused in such structures to meet safety requirements defined in normative acts. Also, the mass of the machines extents up to $30,000 \mathrm{~kg}$. Therefore, the ROPS should protect the residual space outlined by the DLV model. [2].

Myers and Pana-Cryan [3] related three strategies that prevents injuries experienced as an outcome of mining machine overturns. The three strategies were 'install FOPS, 'replace machines cabin' and 'do nothing'. They resolved that the preferred strategy in the case of cost effectiveness was the 'install FOPS' strategy on mining machines in which the FOPS were available. [4]

\section{Three Dimensional Cad Models and Meshing}

The ROPS with ribs and without ribs are designed on the basis of required dimensions as per the safety norms. They are imported and meshed the images are shown below.

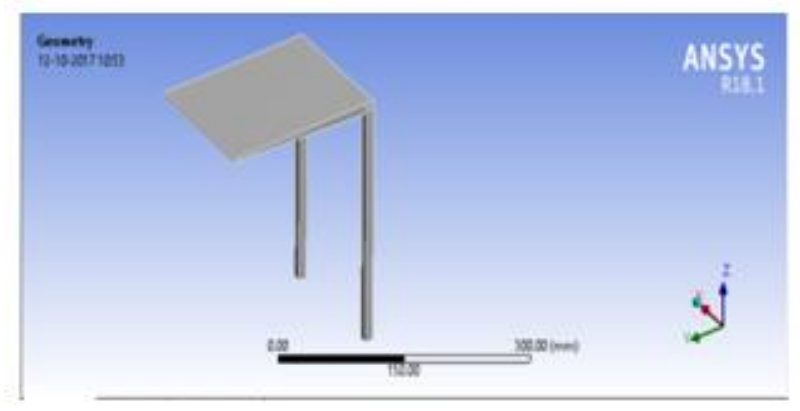

Fig. 1: ROPS without RIBS

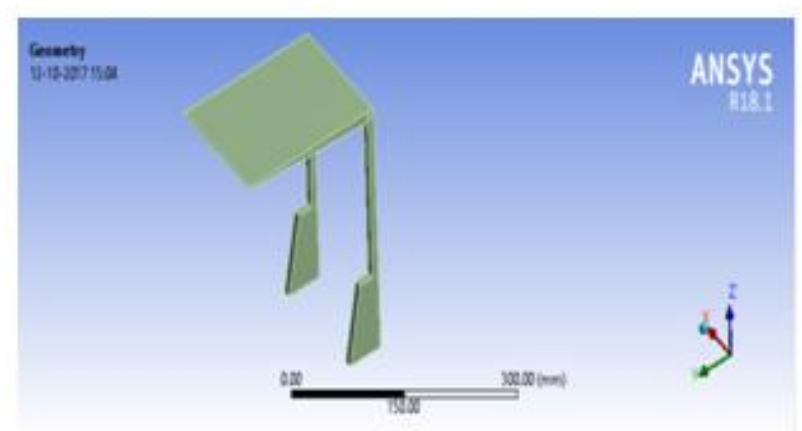

Fig. 2: ROPS with RIBS 

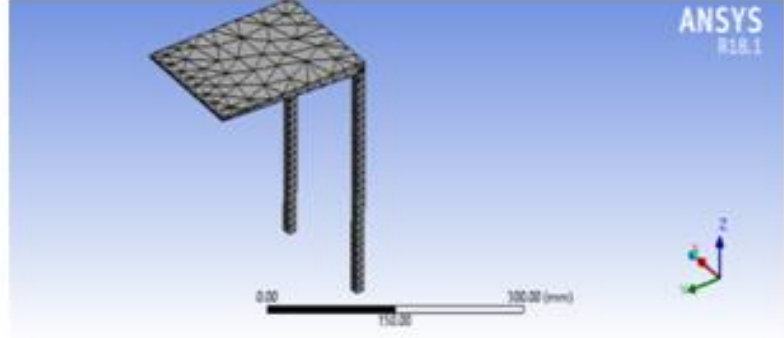

Fig. 3: ROPS without RIBS Meshed

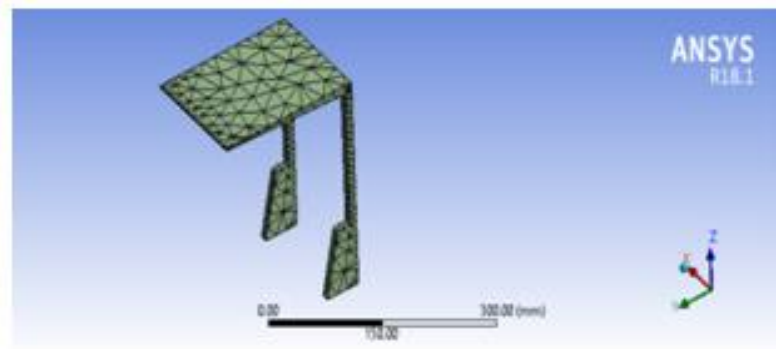

Fig. 4: ROPS with RIBS Meshed

\section{Model Calculation}

As per ISO 3471, the lateral load of $413918.89 \mathrm{~N}$ has been applied for the mass of $50000 \mathrm{Kg}$ on the ROPS. The lateral load was found by the expression $\mathrm{FL}=60000^{*}(\mathrm{M} / 10000) 1.20$.

\section{Comparision of ROPS with RIBS and Without Ribs}

The structures are analyzed using ANSYS 15.0 to determine the total deformation for 6 different frequencies and 6 mode shapes are obtained.

The comparison results clearly suggest that deformation values of ROPS with RIBS are significantly lower compared to without RIBS. Below are the compared figures with caption.
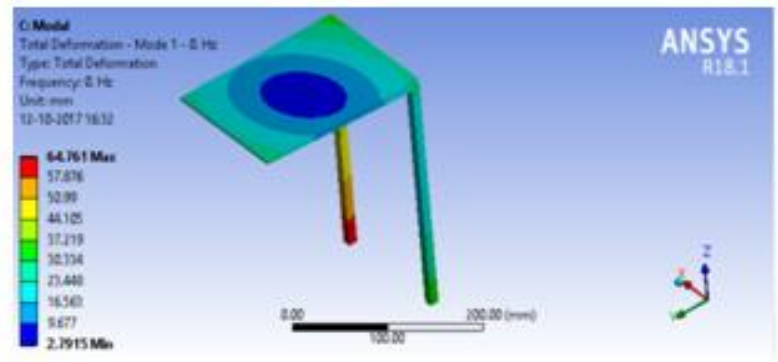

Fig. 5: Total Deformation Mode 1 at $0 \mathrm{HZ}$ of ROPS without RIBS

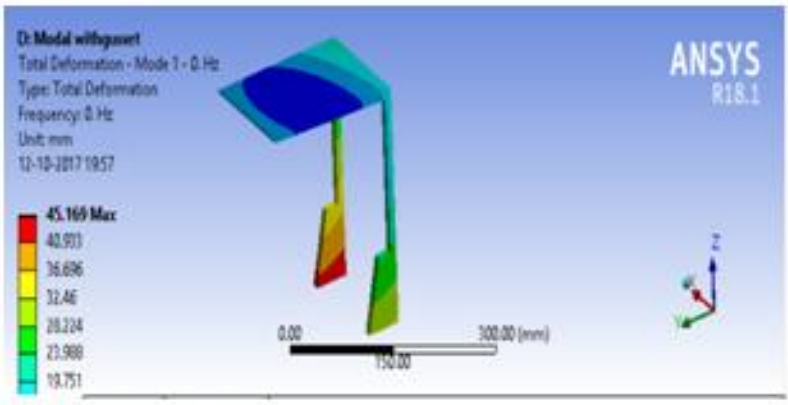

Fig. 6: Total Deformation Mode 1 at $\mathrm{OHZ}$ of ROPS with RIBS

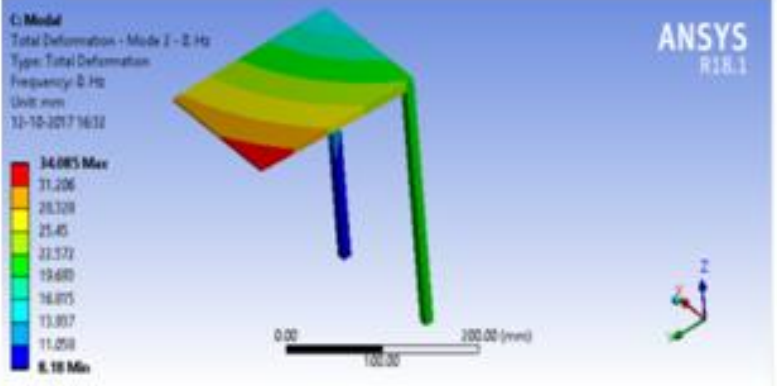

Fig. 7: Total Deformation Mode 2 at $0 \mathrm{HZ}$ of ROPS without RIBS

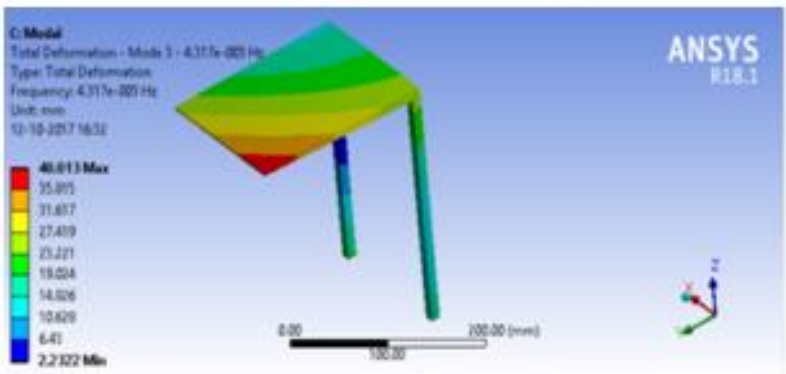

Fig. 8: Total Deformation Mode 3 at $4.317 \mathrm{e}-003 \mathrm{HZ}$ of ROPS without RIBS

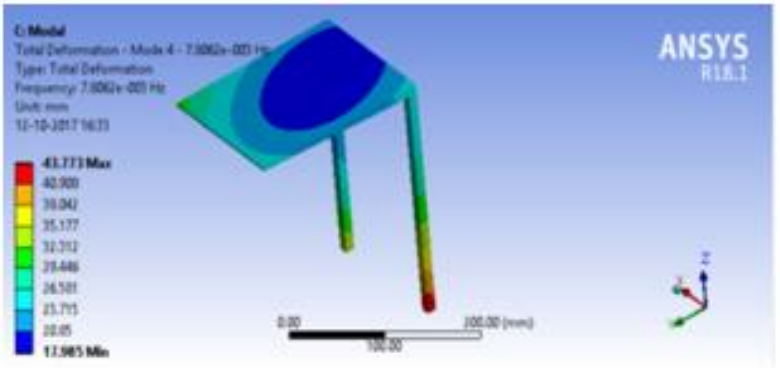

Fig.9: Total Deformation Mode 4 at 7.8062e-003 HZ of ROPS without RIBS

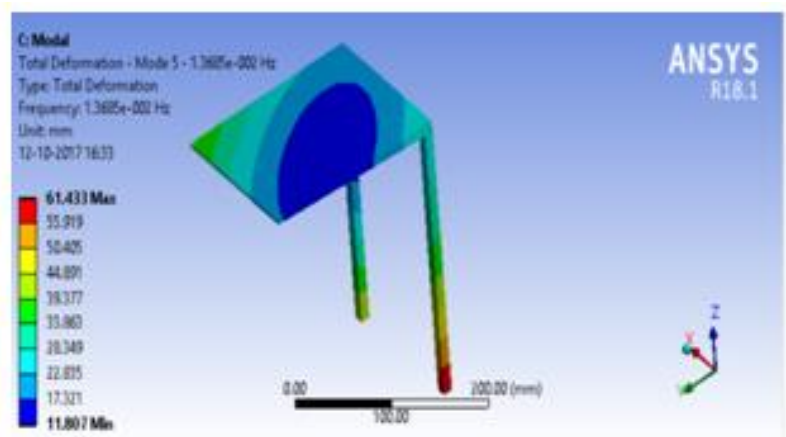

Fig. 10: Total Deformation Mode 5 at $1.3685 \mathrm{e}-002 \mathrm{HZ}$ of ROPS without RIBS

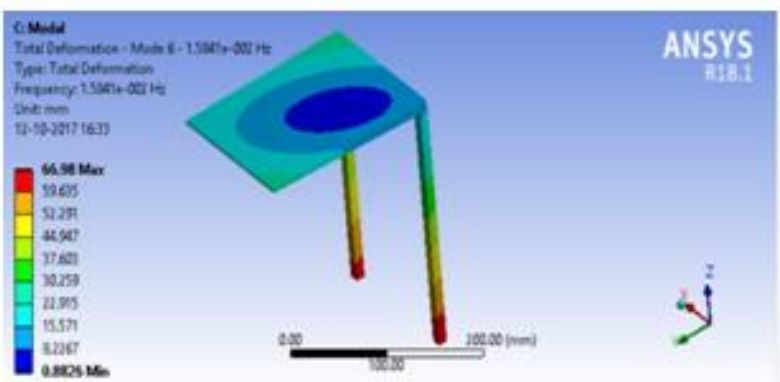

Fig.11: Total Deformation Mode 6 at 1.5841e-002 HZ of ROPS without RIBS 


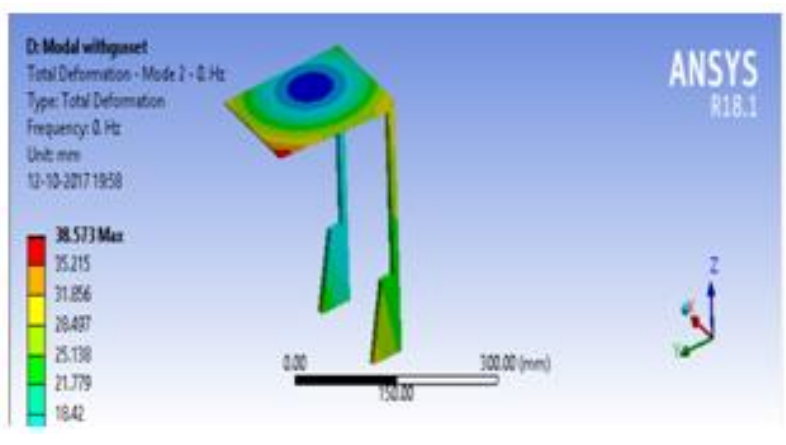

Fig. 12: Total Deformation Mode 2 at $0 \mathrm{HZ}$ of ROPS with RIBS

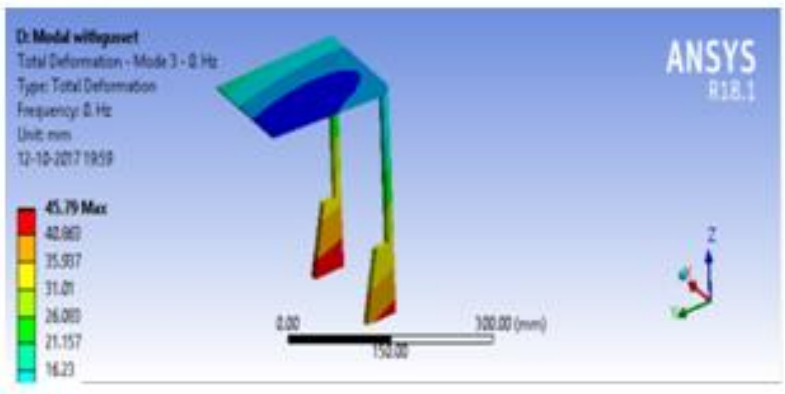

Fig.13: Total Deformation Mode 3 at 4.317e-003 HZ of ROPS with RIBS

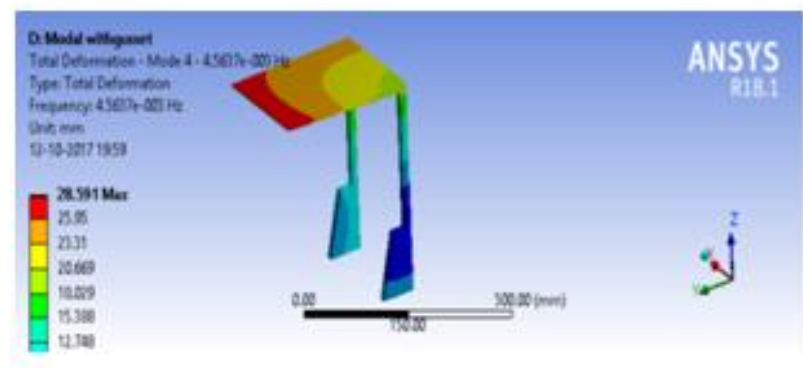

Fig.14: Total Deformation Mode 4 at $7.8062 \mathrm{e}-003 \mathrm{HZ}$ of ROPS with RIBS

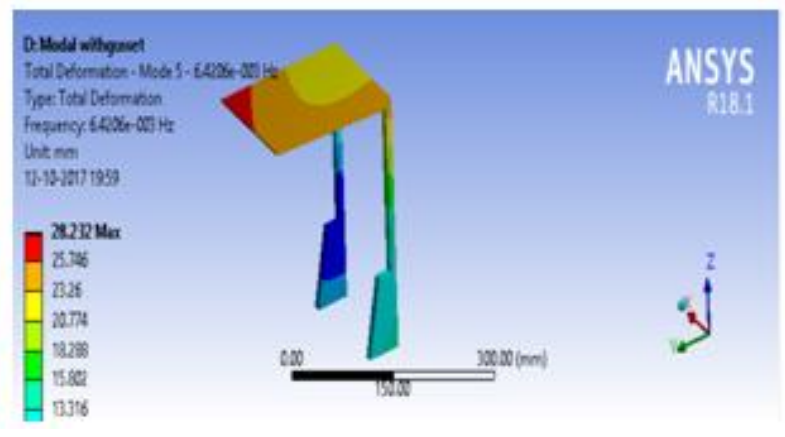

Fig.15: Total Deformation Mode 5 at 1.368 ee-002 HZ of ROPS with RIBS

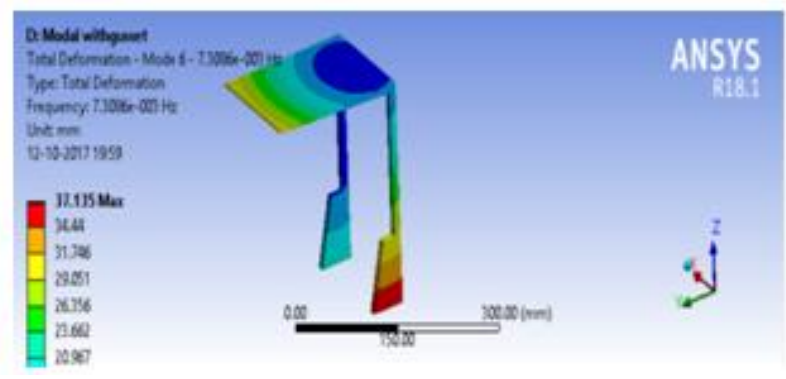

Fig.16 Total Deformation Mode 6 at 1.5841e-002 HZ of ROPS with RIBS
The table showing the values of frequencies at different modes for both ROPS without RIBS and ROPS with RIBS are shown below.

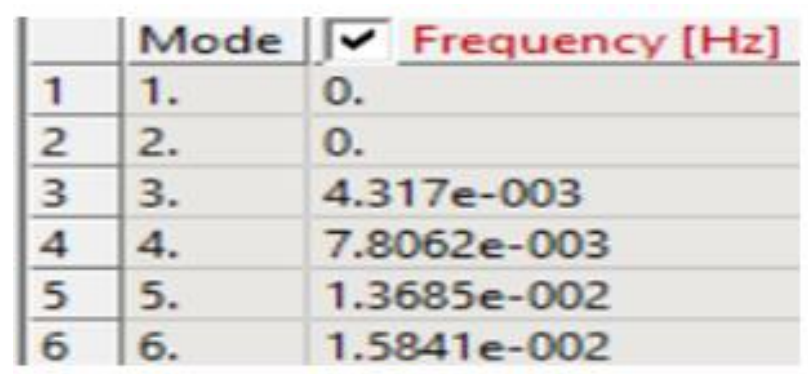

\begin{tabular}{|l|l|l|}
\hline & Mode & $\sqrt{-}$ Frequency $[\mathrm{Hz}]$ \\
\hline 1 & 1. & 0. \\
\hline 2 & 2. & 0. \\
\hline 3 & 3. & 0. \\
\hline 4 & 4. & $4.5637 \mathrm{e}-003$ \\
\hline 5 & 5. & $6.4206 \mathrm{e}-003$ \\
\hline 6 & 6. & $7.3086 \mathrm{e}-003$ \\
\hline
\end{tabular}

\section{Results and Discussion}

The analysis results of ROPS with RIBS and without RIBS are tabulated below.

\begin{tabular}{|l|l|l|}
\hline Mode & $\begin{array}{l}\text { Total Deformation at } \\
\text { ROPS without RIBS }\end{array}$ & $\begin{array}{l}\text { Total } \\
\text { Deformation at } \\
\text { ROPS with } \\
\text { RIBS }\end{array}$ \\
\hline 1. & $64.761 \mathrm{~mm}$ & $45.169 \mathrm{~mm}$ \\
\hline 2. & $34.206 \mathrm{~mm}$ & $38.573 \mathrm{~mm}$ \\
\hline 3. & $40.013 \mathrm{~mm}$ & $45.79 \mathrm{~mm}$ \\
\hline 4. & $43.773 \mathrm{~mm}$ & $28.591 \mathrm{~mm}$ \\
\hline 5. & $61.433 \mathrm{~mm}$ & $28.232 \mathrm{~mm}$ \\
\hline 6. & $66.98 \mathrm{~mm}$ & $37.135 \mathrm{~mm}$ \\
\hline
\end{tabular}

\section{Conclusion}

1. The impact tests are made on the ROPS and the non-linear structural deformation results are formulated. But few plastic deformations may occur which can be neglected.

2. When the ROPS is subjected to the calculated loads, the nonlinear structural deformation is observed.

3. The ROPS with gusset, having cross section and dimension with least effect of the loading conditions were considered for the design and analysis aspects. The behavior of the ROPS is observed by FEA analysis at the ANSYS software.

4. The analysis of the ROPS concludes that the conditions during rolling over of the heavy machines doesn't collapse the structure.

5. The results proves that non-linear structural deformations are within the desirable limits and the ROPS with gusset satisfies the ISO 3471 standards.

\section{Acknowledgment}

This Research is supported by Department of Mechanical Engineering, Karpagam College of Engineering, Myleripalyam, Coimbatore-641032, India making this important research viable and effective. 


\section{References}

[1] Jacek Karlinski, Eugeniusz Rusinski, Tadeusz Smolnicki, Protective structures for construction and mining machine operators, Automation in Construction, volume no-17 (2008) page no- 232-244

[2] J. Karlinski, M. Ptak, P. Dzialak, Simulation test of roll-over protection structure, Archive of civil \& mechanical engineering, volume no- 13 (2013) page no- 57-63.

[3] Regina Pana-Cryan, Melvin L Meyers, Cost-effectiveness of rollover protective structures.

[4] J. Manado, J.I Arana, C. Jaren, Design calculation on roll-over protection structure for agriculture tractor, Bio-system engineering, Volume no- 96 (2007) Page no- 181-191.

[5] Vamshi Chennuri, Harish Kothagadi, Riyazuddin Mohammad, Design and Stress Analysis of Four-post Rollover Protective Structure of Agricultural-Wheeled Tractor, Int. J. Mech. Eng. \& Rob. Res. 2015, ISSN 2278 - 0149.

[6] Prakash Gore, R.B. Barjibhe, Design of Protective structure of operator cabin against falling object (FOPS), International Journal of Latest Trends in Engineering and Technology (IJLETET), Vol 3 Issue 4 March 2014, ISSN: 2278-621X.

[7] Sergio Baragetti, Franco Robolotti, Fabio Rota, Development of a Model for the Simulation of ROPS Tests on Agricultural Tractors Cabin: Numerical Models and Experimental Verification, Int. Journal of Engineering Research and Applications ISSN: 2248 9622, Vol. 5 Issue 9, (Part- 3) September 2015, pp.76-86.

[8] Vidya Pardeshi Design of ROPS (Roll Over Protective Structure) For Operator Cabin International Journal on Future Revolution in Computer Science \& Communication Engineering, Volume: 1 Issue: 2 July 2015, ISSN: 2454-4248.

[9] Dipak Patil, Naresh Oza, ROPS: FEA-Test correlation for excavator cabin ( $<6 \mathrm{~T}$ category), ISO 3471, Driving Innovation with Enterprise Simulation.

[10] Jacek Karlinski, Mariusz Ptak, Paulina Działak, Simulation tests of roll-over protection structure, archives of civil and mechanical engineering 13 (2013) 57-6358. 